\title{
CÁDMIO, CROMO, CHUMBO E ZINCO EM PLANTAS DE MILHO E EM LATOSSOLO APÓS NOVE APLICAÇÕES ANUAIS DE LODO DE ESGOTO ${ }^{(1)}$
}

\author{
Thiago Assis Rodrigues Nogueira ${ }^{(2)}$, Leyser Rodrigues Oliveira ${ }^{(3)}$, \\ Wanderley José de Melo ${ }^{(4)}$, Ivana Machado Fonseca ${ }^{(3)}$, Gabriel \\ Maurício Peruca de Melo ${ }^{(5)}$, Valéria Peruca de Melo ${ }^{(5)} \&$ Marcos \\ Omir Marques ${ }^{(4)}$
}

\begin{abstract}
RESUMO
As maiores limitações para o uso do lodo de esgoto em áreas agrícolas são os riscos de contaminação do solo com metais pesados e sua possível transferência para a cadeia alimentar. Objetivou-se, com este estudo, avaliar os teores de $\mathrm{Cd}$, $\mathrm{Cr}$, $\mathrm{Pb}$ e $\mathrm{Zn}$ no solo, utilizando-se dois métodos de extração $\left(\mathrm{HNO}_{3}+\mathrm{H}_{2} \mathrm{O}_{2}+\mathrm{HCl}\right.$ e $\mathrm{HClO}_{4}+\mathrm{HF}$ ), o acúmulo destes elementos em plantas de milho cultivadas em Latossolo Vermelho eutroférrico no nono ano de aplicação de lodo de esgoto, bem como seus efeitos na produção de matéria seca e na produtividade de grãos. $O$ experimento foi instalado em condições de campo em Jaboticabal-SP, no delineamento em blocos casualizados, com quatro tratamentos e cinco repetições. Os tratamentos corresponderam a doses acumuladas por nove anos consecutivos de lodo de esgoto $\left(45,0 ; 90,0\right.$ e $127,5 \mathrm{t} \mathrm{ha}^{-1}$, base seca) e um tratamento testemunha que recebeu fertilização mineral com base na análise de solo. O lodo de esgoto foi aplicado manualmente e incorporado ao solo com grade a $0,1 \mathrm{~m}$ de profundidade antes da semeadura do milho. Os teores médios de Cd no solo não variaram em função das doses de lodo e dos métodos de extração. Por outro lado, os teores médios de $\mathrm{Cr}, \mathrm{Pb}$ e $\mathrm{Zn}$ no solo obtidos pela digestão com $\mathrm{HClO}_{4}+\mathrm{HF}$ foram de 72,4; 31,8 e $62,3 \%$, respectivamente, superiores àqueles encontrados pela digestão que
\end{abstract}

\footnotetext{
(1) Recebido para publicação em dezembro de 2007 e aprovado em setembro de 2008.

(2) Doutorando em Ciências, Centro de Energia Nuclear na Agricultura, Universidade de São Paulo - CENA/USP. Laboratório de Nutrição Mineral de Plantas, Caixa Postal 96, CEP 13400-970 Piracicaba (SP). Bolsista FAPESP. E-mail: tarnogueira@gmail.com

${ }^{(3)}$ Doutorando em Agronomia (Produção Vegetal), FCAV/UNESP. Bolsistas CAPES e FAPESP. E-mail: leyser@fcav.unesp.br; ivanamf@click21.com.br

(4) Professor do Departamento de Tecnologia, FCAV/UNESP. E-mail: wjmelo@fcav.unesp.br; omir@fcav.unesp.br

(5) Pesquisador do Departamento de Tecnologia, FCAV/UNESP. E-mail: gmpmelo@terra.com.br; vpmelo@bol.com.br
} 
empregou $\mathrm{HNO}_{3}+\mathrm{H}_{2} \mathrm{O}_{2}+\mathrm{HCl}$. Contudo, quando se avaliou apenas o efeito das doses de lodo no solo, em ambos os métodos de extração, verificou-se diferença entre os tratamentos apenas para a concentração de $\mathrm{Zn}$ no solo. Exceto o Cd, que não foi detectado, de modo geral, os teores e os acúmulos de $\mathrm{Cr}$, $\mathrm{Pb}$ e $\mathrm{Zn}$ nas partes das plantas de milho aumentaram com as aplicações de lodo de esgoto. Os teores de $\mathrm{Cr}, \mathrm{Pb}$ e $\mathrm{Zn}$ nos grãos, quando detectados, permaneceram abaixo dos limites máximos estabelecidos para o consumo humano conforme a legislação brasileira. A adição de lodo de esgoto e a fertilização mineral, por longo período, apresentaram efeitos semelhantes na produção de matéria seca e na produtividade de grãos de milho.

Termos de indexação: Zea mays L., biossólido, elementos-traço, poluição do solo, metais pesados, resíduo.

\title{
SUMMARY: CADMIUM, CHROMIUM, LEAD AND ZINC IN MAIZE PLANTS AND OXISOL AFTER NINE ANNUAL APPLICATIONS OF SEWAGE SLUDGE
}

\begin{abstract}
A major limitation for using sewage sludge in agriculture is the risk of soil contamination with heavy metals and their possible transference to humans via food chain. The objective of this study was to evaluate the soil content of $\mathrm{Cd}, \mathrm{Cr}, \mathrm{Pb}$, and $\mathrm{Zn}$ by two digestion methods $\left(\mathrm{HNO}_{3}+\mathrm{H}_{2} \mathrm{O}_{2}+\mathrm{HCl}\right.$ and $\left.\mathrm{HClO}_{4}+\mathrm{HF}\right)$ in maize plants grown on a Typic Eutrorthox soil treated with sewage sludge for nine consecutive years, and the effects on dry matter and grain yield. The experiment was carried out under field conditions in Jaboticabal, State of São Paulo, in a randomized block design with four treatments and five replicates.

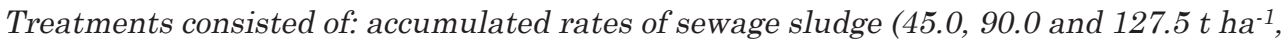
dry basis) applied during nine consecutive years and a control treated with mineral fertilizers according to soil analysis. Sewage sludge was manually applied to the soil and incorporated at a depth of $0.1 \mathrm{~m}$ prior to maize sowing. The mean $C d$ concentration in soil was not affected by sewage sludge rates and extraction methods. On the contrary, the mean soil concentrations of $\mathrm{Cr}, \mathrm{Pb}$ and $\mathrm{Zn}$ extracted by $\mathrm{HClO}_{4}+\mathrm{HF}$ were $72.4,31.8$ and $62.3 \%$, respectively, higher than those obtained by the $\mathrm{HNO}_{3}+\mathrm{H}_{2} \mathrm{O}_{2}+\mathrm{HCl}$. However, when the effect of sewage sludge rates was evaluated, it was verified that only soil $\mathrm{Zn}$ concentration was affected by the treatments. Except for $C d$, which was not detected, the accumulated contents of $\mathrm{Cr}, \mathrm{Pb}$ and $\mathrm{Zn}$ in the different parts of maize plants were generally affected by successive applications of sewage sludge to the soil. Heavy metal contents in the grains, when detected, were in the acceptable range for human consumption, according to Brazilian legislation. The effects of long-term sewage sludge and mineral soil fertilization on dry matter and grain yield were similar.
\end{abstract}

Index terms: Zea mays L., biosolid, trace elements, soil pollution, heavy metals, waste.

\section{INTRODUÇÃO}

A crescente população dos centros urbanos é importante produtora de diversos resíduos, os quais, muitas vezes, são acumulados no ambiente sem o adequado tratamento ou utilização que possibilite sua reciclagem. Dentre esses resíduos, pode-se destacar o lodo de esgoto resultante do tratamento das águas servidas. Por ser gerado em larga escala, esse resíduo é uma fonte constante de preocupação no que se refere à contaminação ambiental (Rocha et al., 2003).

Por muito tempo, os projetos de tratamento de esgotos foram elaborados e executados sem que houvesse previsão para uma destinação adequada para o lodo de esgoto gerado nas estações de tratamento. Recentemente, os órgãos ambientais passaram a exigir projetos que contemplem também o gerenciamento do lodo, como forma de resguardar a saúde humana e o ambiente (CETESB, 1999; CONAMA, 2006).

De composição bastante variada em conseqüência de peculiaridades regionais e dos processos em que é gerado, o lodo de esgoto contém considerável percentual de matéria orgânica e elementos essenciais às plantas, podendo substituir, ainda que parcialmente, os fertilizantes industriais, desempenhando importante papel na produção agrícola e na manutenção da fertilidade do solo (Nascimento et al., 2004). 
A grande produção de lodo de esgoto, principalmente nos centros urbanos, levou pesquisadores a intensificarem os estudos para utilização desses resíduos para fins agrícolas. No Brasil, diversos experimentos vêm sendo desenvolvidos, destacandose o uso do lodo na recuperação de áreas degradadas e como fertilizante em diversas culturas, como sorgo, milho, feijão e cana-de-açúcar (Melo \& Marques, 2000).

Embora a utilização agrícola de lodo de esgoto se apresente como uma das alternativas mais atrativas para a disposição final desse resíduo, elementos potencialmente tóxicos podem limitar sua aplicação, em virtude da possibilidade de contaminação do solo, dos sistemas aquáticos e da atmosfera, aumentando o risco de transferência deles para a cadeia alimentar (Gomes et al., 2006; Nogueira et al., 2007).

A reciclagem do lodo de esgoto na agricultura tem resultado em acúmulo de metais pesados nos solos, em especial $\mathrm{Cd}, \mathrm{Cr}, \mathrm{Ni}, \mathrm{Pb}$ e $\mathrm{Zn}$, principalmente quando o resíduo é originado de áreas industriais (Krebs et al., 1998).

A obtenção de dados sobre o acúmulo de metais pesados no solo, ao longo do tempo, é realizada por meio da determinação dos teores totais desses elementos, sendo, na maioria dos estudos, realizada por meio da digestão de amostras de solo com ácido fluorídrico (HF) juntamente com outros ácidos fortes, que promove a dissolução total da amostra. Contudo, o uso de HF na rotina de laboratórios é pouco recomendado, por se tratar de um reagente altamente corrosivo, de difícil manuseio e altamente tóxico ao homem (Silva et al., 2006). Por esse motivo, segundo Abreu et al. (1996), há preferência pelo uso de ácidos fortes, como $\mathrm{HNO}_{3}$, ou mistura de ácidos, como ácidos nítrico e perclórico $\left(\mathrm{HNO}_{3}+\mathrm{HClO}_{4}-5: 1\right)$, ou água régia $\left(\mathrm{HNO}_{3}+\mathrm{HCl}-3: 1\right)$, mesmo que os resultados não representem os teores totais dos metais no solo.

A preocupação com a disponibilidade de metais pesados no solo em função das sucessivas aplicações de lodo de esgoto e sua possível transferência para a planta, em especial para a cultura do milho, tem sido crescente nos trabalhos de pesquisa em ciência do solo no Brasil (Martins et al., 2003; Oliveira et al., 2005; Rangel et al., 2006; Nogueira et al., 2007).

$\mathrm{O}$ acúmulo de metais pesados nas plantas pode ocorrer sem que haja manifestação de sintomas de toxicidade e prejuízo para a produção das culturas (Jeevan Rao \& Shantaran, 1996); entretanto, poderá interferir na qualidade dos alimentos, conforme verificado por Santos et al. (2002). Portanto, conhecer o destino desses elementos é essencial para a avaliação do impacto ambiental provocado pelo uso do lodo de esgoto em solos agrícolas.

Nesse contexto, objetivou-se com este estudo avaliar os teores de $\mathrm{Cd}, \mathrm{Cr}, \mathrm{Pb}$ e $\mathrm{Zn}$ no solo, o acúmulo destes elementos em partes de plantas de milho cultivadas em solo tratado com lodo de esgoto por nove anos consecutivos e seus efeitos na produção de matéria seca e na produtividade de grãos de milho.

\section{MATERIAL E MÉTODOS}

O experimento foi realizado em campo na fazenda de ensino e pesquisa da Faculdade de Ciências Agrárias e Veterinárias da UNESP, campus de JaboticabalSP, Brasil (21 15' 22 " S e 48 $15^{\prime}$ ' 18 " W, altitude de $618 \mathrm{~m}$ ), utilizando-se delineamento experimental em blocos casualizados com quatro tratamentos e cinco repetições, tendo início no ano agrícola 1997/98.

$\mathrm{Na}$ instalação inicial do experimento, o solo foi arado e gradeado, aplicando-se em seguida $2,5 \mathrm{t} \mathrm{ha}^{-1}$ de calcário dolomítico (PRNT = $90 \%$ ), de acordo com as recomendações de Raij \& Cantarella (1997). Neste mesmo ano, os tratamentos corresponderam a: 0,0 (testemunha, sem aplicação de lodo de esgoto e de fertilizantes minerais); 2,5; 5,0; e 10,0 $\mathrm{t} \mathrm{ha}^{-1}$ de lodo de esgoto, base seca. A dose de $5 \mathrm{t} \mathrm{ha}^{-1}$ de lodo de esgoto foi estabelecida para fornecer o $\mathrm{N}$ exigido pela cultura, admitindo-se que $1 / 3$ do $\mathrm{N}$ contido no resíduo estaria disponível para as plantas (CETESB, 1999). Dessa forma, a dose de aplicação do resíduo orgânico, em tha-1 ${ }^{-1}$ foi definida pelo quociente entre a quantidade de $\mathrm{N}$ recomendada para a cultura em $\mathrm{kg} \mathrm{ha}^{-1}$, conforme o Boletim 100 (Raij \& Cantarella, 1997), e o teor estimado de $\mathrm{N}$ disponível no lodo em $\mathrm{g} \mathrm{kg}{ }^{-1}$.

A partir do segundo ano de experimentação, optouse por adubar (aplicação de N, P e K) o tratamento testemunha, de acordo com os resultados da análise de fertilidade do solo e as indicações contidas em Raij \& Cantarella (1997). A partir de 2000, com base nos resultados até então obtidos, optou-se por aumentar a dose de 2,5 t ha $^{-1}$ para $20 \mathrm{t} \mathrm{ha}^{-1}$ de lodo de esgoto, base seca. Dessa forma, os tratamentos em doses acumuladas nos nove anos foram: 0,0 (testemunha = sem aplicação de lodo de esgoto e com fertilização mineral); 45,0; 90,0 e 127,5 $\mathrm{tha}^{-1}$ de lodo de esgoto, base seca.

O milho (Zea mays L.) foi a cultura avaliada até o sexto ano. No sétimo ano, utilizou-se o girassol (Helianthus annuus L.); no oitavo ano, a crotalária (Crotalaria juncea L.); e no nono ano, novamente o milho.

O solo da área experimental é um Latossolo Vermelho eutroférrico (LVef) textura argilosa A moderado caulinítico (Embrapa, 2006). A amostragem do solo para caracterização química $(0-20 \mathrm{~cm}$ de profundidade) foi feita antes da instalação do experimento (Quadro 1), conforme os protocolos analíticos descritos em Raij et al. (2001).

Com base na análise de solo realizada antes da instalação do experimento no nono ano, constatou-se a necessidade de elevar a saturação por bases para $70 \%$ nas parcelas que representavam os tratamentos testemunha e $20 \mathrm{t} \mathrm{ha}^{-1}$ de lodo de esgoto, aplicando-se 1,8 e 2,5 t ha ${ }^{-1}$ de calcário dolomítico $(\mathrm{PRNT}=$ $90 \%$ ), respectivamente, de acordo com Raij \& Cantarella (1997).

O lodo de esgoto utilizado nos nove anos de experimentação foi obtido na Estação de Tratamento 
de Esgoto (ETE) da Companhia de Saneamento Básico do Estado de São Paulo (SABESP), em Barueri, região Metropolitana de São Paulo-SP, com características químicas apresentadas no quadro 2.

A concentração de $\mathrm{N}$ total no lodo de esgoto foi determinada por destilação a vapor no extrato de digestão sulfúrica (Bremner et al., 1996); o P, por espectrofotometria; o K, por fotometria de chama no extrato de digestão nítrico-perclórica (Malavolta et al., 1997); e os demais elementos, por espectrofotometria de absorção atômica (equipamento marca GBC, modelo Avanta, com respectivos comprimentos de onda em $\mathrm{cm}: \mathrm{Cu}=324,7 ; \mathrm{Mn}=403,1 ; \mathrm{Zn}=213,9 ; \mathrm{Cr}=357,9$; $\mathrm{Cd}=228,8 ; \mathrm{Ni}=232,0 ;$ e $\mathrm{Pb}=217,0)$ com chama de ar-acetileno (chama acetileno-óxido nitroso para o $\mathrm{Cr}$ ) no extrato da digestão com $\mathrm{HNO}_{3}+\mathrm{H}_{2} \mathrm{O}_{2}+\mathrm{HCl}$ (USEPA-3050, 1986).

A aplicação do lodo de esgoto ao solo, no ano agrícola 2005/06, foi feita no mês de outubro, levando-se em conta a umidade do resíduo (80 \%) determinada antes da aplicação. Para determinação da umidade, foram retiradas três subamostras, as quais foram secas em estufa a $100-105^{\circ} \mathrm{C}$ até massa constante. Pela diferença de massa antes e após a secagem, foi determinada a umidade do material, o que permitiu calcular as quantidades de lodo úmido necessárias a serem distribuídas em cada unidade experimental para obtenção das doses correspondentes aos tratamentos aplicados ao solo. O lodo aplicado nas parcelas foi distribuído a lanço, de forma manual, sendo posteriormente incorporado ao solo a aproximadamente 0,1 m de profundidade com uma gradagem leve.

Os fertilizantes minerais, no tratamento testemunha, foram aplicados nos sulcos de semeadura de forma manual, como segue: a adubação de semeadura foi feita utilizando-se, por hectare, $30 \mathrm{~kg}$ de $\mathrm{N}$ (sulfato de amônio), $50 \mathrm{~kg}$ de $\mathrm{P}_{2} \mathrm{O}_{5}$ (superfosfato simples) e $50 \mathrm{~kg}$ de $\mathrm{K}_{2} \mathrm{O}$ (cloreto de potássio). Nos tratamentos com lodo de esgoto, o K foi complementado somente nas parcelas tratadas com a dose de $5 \mathrm{t} \mathrm{ha}^{-1}$, sendo aplicados $24 \mathrm{~kg} \mathrm{ha}^{-1}$ de $\mathrm{K}_{2} \mathrm{O}$ (cloreto de potássio). As quantidades de $\mathrm{N}$ e $\mathrm{P}$, nas parcelas que receberam

Quadro 1. Alguns atributos químicos do Latossolo Vermelho eutroférrico conforme as doses de lodo de esgoto, antes da instalação do experimento (ano agrícola 2004/05)

\begin{tabular}{|c|c|c|c|c|c|c|c|c|c|c|}
\hline Lodo de esgoto $^{(1)}$ & $\mathrm{pH} \mathrm{CaCl}_{2}$ & MO & $P$ resina & $\mathbf{K}$ & $\mathbf{C a}$ & Mg & $\mathrm{H}+\mathrm{Al}$ & SB & CTC & $\mathbf{V}$ \\
\hline $\mathrm{tha}^{-1}$ & & $\mathrm{~g} \mathrm{dm}^{-3}$ & $\mathrm{mg} \mathrm{dm}^{-3}$ & $\longrightarrow$ & 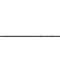 & - & $\mathrm{ll}_{\mathrm{c}} \mathrm{dm}^{-3}$ & & - & $\%$ \\
\hline $0,0^{(2)}$ & 5,1 & 25 & 58 & 4,8 & 29 & 12 & 42 & 46 & 88 & 52 \\
\hline 40,0 & 5,3 & 27 & 65 & 3,9 & 41 & 13 & 38 & 58 & 96 & 60 \\
\hline 80,0 & 5,6 & 28 & 132 & 4,1 & 58 & 13 & 31 & 75 & 106 & 71 \\
\hline 107,5 & 5,0 & 28 & 88 & 4,1 & 32 & 10 & 52 & 46 & 98 & 47 \\
\hline
\end{tabular}

${ }^{(1)}$ Doses acumuladas após oito aplicações anuais. ${ }^{(2)}$ Fertilização mineral. MO: matéria orgânica; SB: soma de bases; CTC: capacidade de troca de cátions; V: saturação por bases.

Quadro 2. Teores de alguns elementos químicos das amostras de lodo de esgoto (base seca) proveniente da Estação de Tratamento de Esgoto (ETE) de Barueri-SP, utilizado nos nove anos de experimentação

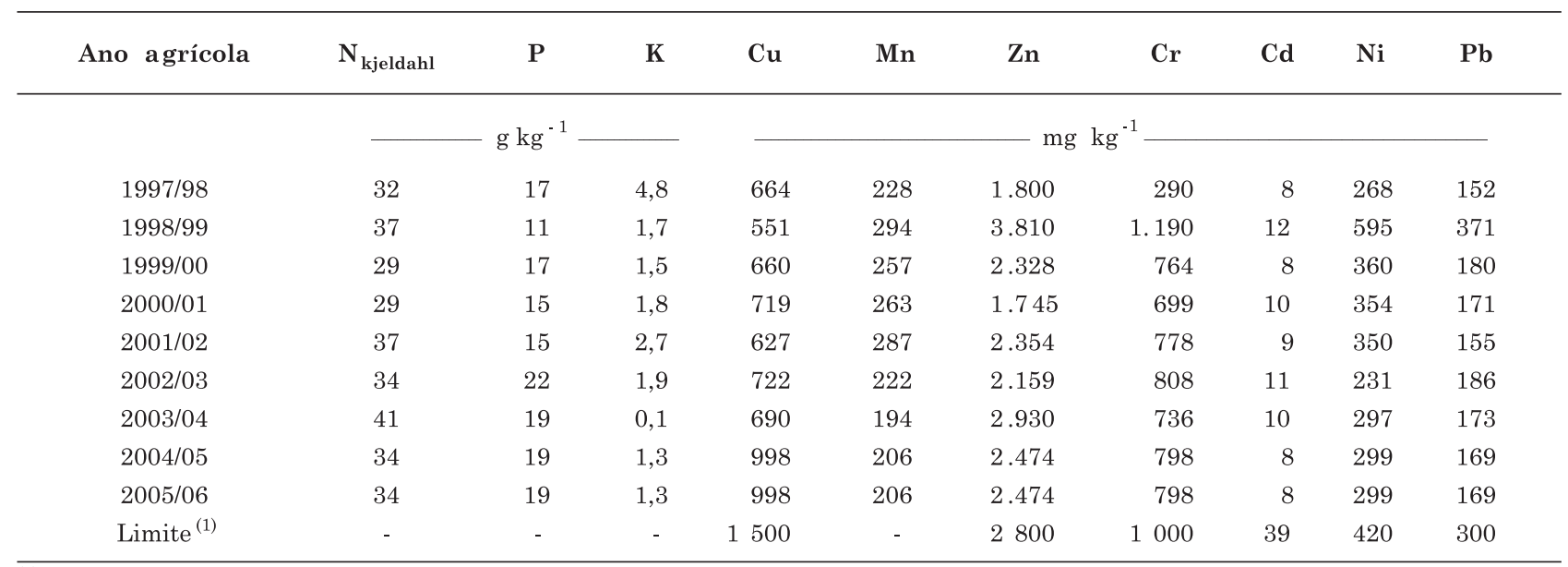

(1) Concentração máxima permitida de metais pesados no lodo de esgoto para uso na agricultura conforme normas do CONAMA (2006). 
lodo, encontravam-se dentro do requerido pela cultura (Raij \& Cantarella, 1997).

Foram realizadas duas adubações de cobertura, uma aos 27 dias após a semeadura e outra aos 40 dias, sendo aplicados em cada cobertura $70 \mathrm{~kg} \mathrm{ha}^{-1}$ de $\mathrm{N}$ (uréia) apenas no tratamento que recebeu fertilização mineral e $40 \mathrm{~kg} \mathrm{ha}^{-1}$ de $\mathrm{K}_{2} \mathrm{O}$ (cloreto de potássio) em todos os demais tratamentos. No quadro 3 são apresentadas as doses de $\mathrm{N}, \mathrm{P}_{2} \mathrm{O}_{5}$ e $\mathrm{K}_{2} \mathrm{O}$ aplicadas ao solo nos nove anos agrícolas.

O híbrido de milho escolhido para o ano de 2005/06 foi o Syngenta NK Traktor S1, sendo adotado o espaçamento de 0,9 m entre linhas, com oito plantas por metro linear e parcela experimental de $60 \mathrm{~m}^{2}$. A semeadura ocorreu no dia 26 de novembro de 2005. As plantas daninhas foram controladas por meio de aplicação de herbicida (glifosato).

Aos 60 dias após a emergência das plantas, realizouse uma amostragem de solo para determinação dos teores de $\mathrm{Cd}, \mathrm{Cr}, \mathrm{Pb}$ e $\mathrm{Zn}$. Essas amostras foram retiradas com o auxílio de trado tipo holandês, na linha de semeadura a cerca de $5 \mathrm{~cm}$ ao lado das plantas, na profundidade de $0-20 \mathrm{~cm}$. Na seqüência, as amostras foram secas ao ar, destorroadas e passadas em peneira com $2 \mathrm{~mm}$ de abertura de malha. Em seguida, procedeu-se à digestão das amostras em mistura de ácidos $\left(\mathrm{HNO}_{3}+\mathrm{H}_{2} \mathrm{O}_{2}+\mathrm{HCl}\right)$ conforme o método USEPA (United State Environmental Protection

Quadro 3. Fertilização mineral aplicada no Latossolo Vermelho eutroférrico nos nove anos de experimentação

\begin{tabular}{|c|c|c|c|c|c|c|}
\hline \multirow[b]{2}{*}{ Ano agrícola } & \multirow[b]{2}{*}{ Lodo de esgoto $^{(1)}$} & \multicolumn{2}{|c|}{$\mathbf{N}$} & \multirow{2}{*}{$\begin{array}{c}\mathrm{P}_{2} \mathrm{O}_{5} \\
\text { Semeadura }\end{array}$} & \multicolumn{2}{|c|}{$\mathbf{K}_{2} \mathbf{O}$} \\
\hline & & Semeadura & Cobertura & & Semeadura & Cobertura \\
\hline \multirow{5}{*}{$1997 / 98$} & $\mathrm{tha}^{-1}$ & 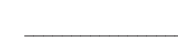 & 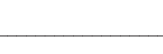 & $\mathrm{g} \mathrm{ha}^{-1}$ & & \\
\hline & 0,0 & - & - & - & - & - \\
\hline & 2,5 & - & - & 50 & 29 & - \\
\hline & 5,0 & - & - & 44 & 26 & - \\
\hline & 10,0 & - & - & 33 & 20 & - \\
\hline \multirow[t]{4}{*}{ 1998/99 } & 0,0 & 15 & 61 & 30 & 30 & - \\
\hline & 5,0 & - & - & - & 25 & - \\
\hline & 10,0 & - & - & - & 20 & - \\
\hline & 20,0 & - & - & - & 10 & - \\
\hline \multirow[t]{4}{*}{$1999 / 00$} & 0,0 & 30 & 110 & 50 & 50 & 40 \\
\hline & 7,5 & - & - & - & 46 & 40 \\
\hline & 15,0 & - & - & - & 41 & 40 \\
\hline & 30,0 & - & - & - & 32 & 40 \\
\hline \multirow[t]{4}{*}{$2000 / 01$} & 0,0 & 30 & 120 & 50 & 50 & 40 \\
\hline & 20,0 & - & - & 16 & 39 & 40 \\
\hline & $2,5^{(2)} 27,5$ & - & - & - & 28 & 40 \\
\hline & 40,0 & - & - & - & 5 & 40 \\
\hline \multirow[t]{4}{*}{$2001 / 02$} & 0,0 & 30 & 140 & 50 & 50 & 40 \\
\hline & 25,0 & - & - & - & 34 & 40 \\
\hline & 47,5 & - & - & - & 17 & 40 \\
\hline & 50,0 & - & - & - & - & 40 \\
\hline \multirow[t]{4}{*}{$2002 / 03$} & 0,0 & 30 & 140 & 50 & 50 & 40 \\
\hline & 30,0 & - & - & - & 38 & 40 \\
\hline & 60,0 & - & - & - & 27 & 40 \\
\hline & 67,5 & - & - & - & 4 & 40 \\
\hline \multirow[t]{4}{*}{$2003 / 04$} & 0,0 & 10 & 40 & 20 & 20 & - \\
\hline & 35,0 & - & - & - & - & 8 \\
\hline & 70,0 & - & - & - & - & - \\
\hline & 87,5 & - & - & - & - & - \\
\hline \multirow[t]{4}{*}{$2004 / 05$} & 0,0 & - & - & 18 & 18 & - \\
\hline & 40,0 & - & - & - & - & - \\
\hline & 80,0 & - & - & - & - & - \\
\hline & 107,5 & - & - & - & - & - \\
\hline \multirow[t]{4}{*}{$2005 / 06$} & 0,0 & 30 & 140 & 50 & 50 & 40 \\
\hline & 45,0 & - & - & - & 24 & 40 \\
\hline & 90,0 & - & - & - & - & 40 \\
\hline & 127,5 & - & - & - & - & 40 \\
\hline
\end{tabular}

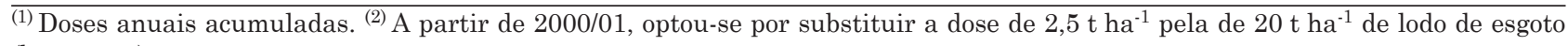
(base seca). 
Agency) 3050 descrito em USEPA (1986) e o método $\left(\mathrm{HClO}_{4}+\mathrm{HF}\right)$ descrito em Jackson (1958). Nos extratos obtidos a partir dos processos de digestão, determinaram-se os teores de $\mathrm{Cd}, \mathrm{Cr}, \mathrm{Pb}$ e $\mathrm{Zn}$ por espectrofotometria de absorção atômica com chama de ar-acetileno (chama acetileno-óxido nitroso para o $\mathrm{Cr})$.

A amostragem das plantas para avaliação dos teores e acúmulos de $\mathrm{Cd}, \mathrm{Cr}, \mathrm{Pb}$ e $\mathrm{Zn}$ foi realizada ao final do ciclo da cultura (abril de 2006). Coletaram-se seis plantas por parcela, as quais foram cortadas rente ao solo e, posteriormente, separadas em colmo, folhas, palha, sabugo e grãos.

O sabugo e os grãos foram colocados em sacos de papel perfurados e secos em estufa com circulação forçada de ar mantida a $60-70{ }^{\circ} \mathrm{C}$. Folhas, colmos e palhas foram lavados em seqüência com solução de água + detergente $\left(1 \mathrm{~mL} \mathrm{~L}^{-1}\right)$, água corrente, água destilada e água deionizada. Após a lavagem, o material vegetal foi acondicionado em sacos de papel e colocado em estufa para secagem, até obtenção da massa constante. Depois de seco, todo o material foi pesado e moído em moinho tipo Willey, dotado de peneira de 40 mesh, acondicionado em sacos de polietileno devidamente identificados e armazenado em câmara seca até o momento das análises.

Os teores de $\mathrm{Cd}, \mathrm{Cr}, \mathrm{Pb}$ e $\mathrm{Zn}$ nas amostras de plantas foram determinados nos extratos obtidos da digestão em $\mathrm{HNO}_{3}+\mathrm{H}_{2} \mathrm{O}_{2}+\mathrm{HCl}$, conforme o método descrito em USEPA-3050 (1986), e quantificados por espectrofotometria de absorção atômica. O limite de detecção para os elementos analisados foi estabelecido usando-se o método descrito em Giné-Rosias (1998).

Com base nos teores dos elementos e na produção de matéria seca, foram calculadas as quantidades acumuladas dos metais pesados no colmo, folhas, palha, sabugo e grãos, pela seguinte fórmula: $\mathrm{A}=\mathrm{T} \times \mathrm{MS}$, em que A é a quantidade acumulada em microgramas por parte da planta; Té o teor do elemento na parte da planta considerada, em $\mathrm{mg} \mathrm{kg}{ }^{-1}$; e MS é a matéria seca da parte da planta considerada, em gramas.

A avaliação da produtividade de grãos de milho foi feita por amostragem, coletando-se espigas das duas linhas centrais de cada parcela do experimento, considerando-se $6 \mathrm{~m}$ por linha, e posteriormente, extrapolando-se os valores obtidos para tonelada de grãos por hectare. Com base no teor de umidade dos grãos colhidos, determinado por gravimetria após secagem em estufa a $105 \pm 3{ }^{\circ} \mathrm{C}$ durante $24 \mathrm{~h}$, procedeu-se à correção para expressar a produtividade com teor de umidade corrigido para 13 \% (Brasil, 1992).

Por ocasião da realização das análises estatísticas, os dados de solo foram agrupados em esquema fatorial $2 \times 4$, ou seja, dois métodos e quatro tratamentos. Para cada variável estudada, os resultados obtidos foram submetidos à análise de variância, seguindo-se a aplicação do teste de Tukey a $5 \%$, utilizando-se o programa estatístico ESTAT (1994), para comparação das médias nos casos em que o teste $\mathrm{F}$ foi significativo (Pimentel-Gomes \& Garcia, 2002). Também foram realizados estudos de correlação entre os teores de metais no solo, o acúmulo destes pelas plantas e a produtividade de grãos de milho.

\section{RESULTADOS E DISCUSSÃO}

Os resultados analíticos das características químicas do lodo de esgoto nos nove anos de experimentação (Quadro 2) foram comparados com os limites determinados pelo CONSELHO NACIONAL DO MEIO AMBIENTE (CONAMA, 2006). Observouse que, exceto para o $\mathrm{Cr}, \mathrm{Ni}, \mathrm{Pb}$ e $\mathrm{Zn}$ no ano agrícola $1998 / 99$ e para o Zn em 2003/04, os teores dos demais metais pesados analisados no lodo de esgoto utilizado foram inferiores aos limites estabelecidos. Entretanto, se esses teores fossem comparados com os permitidos pela norma P 4.230 da Companhia de Tecnologia de Saneamento Ambiental (CETESB, 1999), que estabelece os critérios para o uso do lodo de esgoto na agricultura no Estado de São Paulo, apenas o Ni, no ano agrícola 1998/99, seria superior (420 $\left.\mathrm{mg} \mathrm{kg}^{-1}\right)$.

Quanto aos teores de $\mathrm{Cd}, \mathrm{Cr}, \mathrm{Pb}$ e $\mathrm{Zn}$ no solo (Quadro 4), verificou-se que a interação entre as doses de lodo de esgoto e os métodos estudados não foi significativa. Observou-se também que, exceto para o Zn, não houve efeito das doses de lodo nos teores desses elementos no solo. No método proposto pela USEPA-3050, os teores de Zn foram de 52,99 e $75,01 \mathrm{mg} \mathrm{kg}^{-1}$ nos tratamentos testemunha e 90,0 t ha ${ }^{-1}$ de lodo de esgoto, respectivamente. Com a digestão que empregou $\mathrm{HClO}_{4}+\mathrm{HF}$ proposta por Jackson (1958), os teores de $\mathrm{Zn}$ obtidos foram bem superiores, estando entre $158,71 \mathrm{mg} \mathrm{kg}^{-1}$ no tratamento testemunha e $186,11 \mathrm{mg} \mathrm{kg}^{-1}$ no tratamento com 90,0 t ha-1 de lodo de esgoto (Quadro 4). Esses resultados se assemelham aos obtidos por outros autores (Oliveira \& Mattiazzo, 2001; Martins et al., 2003; Oliveira et al., 2005), que evidenciaram uma contribuição da adição do lodo de esgoto nos teores totais de Zn no solo.

Rangel et al. (2004), que também obtiveram aumentos nos teores totais de $\mathrm{Zn}$ num Latossolo Vermelho cultivado por três anos com milho e que recebeu aplicação de lodo de esgoto oriundo da ETE de Barueri-SP, justificam esses acréscimos pelas altas concentrações desse metal no lodo. De acordo com Silva et al. (2006), o acúmulo de metais pesados no solo, em razão de aplicações sucessivas de lodo de esgoto, é um dos aspectos que mais causam preocupação com relação à segurança ambiental, necessária para a viabilização do uso desse resíduo na agricultura. Entretanto, ao se compararem os teores totais de $\mathrm{Cd}, \mathrm{Cr}, \mathrm{Pb}$ e $\mathrm{Zn}$ no solo com os limites críticos estabelecidos pela USEPA $(1993)(\mathrm{Cd}=20, \mathrm{Cr}=1.530$, $\mathrm{Pb}=180$ e $\mathrm{Zn}=1.460 \mathrm{mg} \mathrm{kg}^{-1}$ ), pela Diretriz da 
Quadro 4. Teores de Cd, Cr, Pb e Zn no Latossolo Vermelho eutroférrico em função do método de extração e das doses acumuladas de lodo de esgoto

\begin{tabular}{|c|c|c|c|c|c|c|}
\hline Dose & de lodo de esgoto ${ }^{(1)}$ & Método & Cd & $\mathbf{C r}$ & $\mathbf{P b}$ & Zn \\
\hline & $\mathrm{tha}^{-1}$ & & \multicolumn{4}{|c|}{$\mathrm{mg} \mathrm{kg}^{-1}$} \\
\hline & $0,0^{(2)}$ & \multirow[t]{5}{*}{$\mathrm{HNO}_{3}+\mathrm{H}_{2} \mathrm{O}_{2}+\mathrm{HCl}^{(3)}$} & 1,87 & 26,82 & 14,49 & $52,99 \mathrm{~b}$ \\
\hline & 45,0 & & 1,90 & 27,50 & 15,19 & $58,47 \mathrm{ab}$ \\
\hline & 90,0 & & 1,98 & 29,57 & 16,53 & 75,01 a \\
\hline & 127,5 & & 1,97 & 30,99 & 16,65 & $72,81 \mathrm{ab}$ \\
\hline & Médias & & $1,93 \mathrm{~A}$ & $28,72 \mathrm{~B}$ & $15,72 \mathrm{~B}$ & $64,82 \mathrm{~B}$ \\
\hline & 0,0 & \multirow[t]{5}{*}{$\mathrm{HClO}_{4}+\mathrm{HF}^{(4)}$} & 1,90 & 107,60 & 22,57 & $158,71 \mathrm{~b}$ \\
\hline & 45,0 & & 2,00 & 102,10 & 22,70 & $165,47 \mathrm{ab}$ \\
\hline & 90,0 & & 2,02 & 109,95 & 23,13 & $186,11 \mathrm{a}$ \\
\hline & 127,5 & & 2,06 & 97,02 & 23,83 & $177,60 \mathrm{ab}$ \\
\hline & Médias & & $1,99 \mathrm{~A}$ & $104,17 \mathrm{~A}$ & $23,05 \mathrm{~A}$ & $171,97 \mathrm{~A}$ \\
\hline \multicolumn{7}{|c|}{ Teste $\mathrm{F}$} \\
\hline & Métodos (M) & & $2,93^{\mathrm{NS}}$ & $1.406,39^{* *}$ & $156,38^{* *}$ & $868,71^{* *}$ \\
\hline & Doses de lodo de esgoto (D) & & $2,06^{\mathrm{NS}}$ & $1,66^{\mathrm{NS}}$ & $1,79^{\mathrm{NS}}$ & $9,91^{* *}$ \\
\hline & $(\mathrm{M} \times \mathrm{D})$ & & $0,18^{\mathrm{NS}}$ & $2,93^{\mathrm{NS}}$ & $0,28^{\mathrm{NS}}$ & $0,15^{\mathrm{NS}}$ \\
\hline & CV $(\%)$ & & 6,4 & 9,6 & 9,6 & 9,7 \\
\hline
\end{tabular}

(1) Doses acumuladas após nove aplicações anuais. ${ }^{(2)}$ Testemunha: somente com fertilização mineral. ${ }^{(3)}$ USEPA-3050 (1986). (4) Jackson (1958). Médias seguidas de mesma letra maiúscula (métodos) e minúscula (doses) na coluna não diferem entre si pelo teste de Tukey a $5 \%$. ${ }^{* *}$ NS: significativo a $1 \%$ e não-significativo.

Comunidade Européia (Ferreira et al., 1999) $(\mathrm{Cd}=1-3$, $\left.\mathrm{Cr}=100-150, \mathrm{~Pb}=50-300 \mathrm{e} \mathrm{Zn}=150-300 \mathrm{mg} \mathrm{kg}^{-1}\right) \mathrm{e}$ pela CETESB $(2005)(\mathrm{Cd}=3, \mathrm{Cr}=150, \mathrm{~Pb}=180 \mathrm{e} \mathrm{Zn}$ $=450 \mathrm{mg} \mathrm{kg}^{-1}$ ), verifica-se que os teores desses elementos neste estudo estavam dentro dos valores permitidos para áreas agrícolas, mesmo com as aplicações sucessivas de lodo de esgoto.

Em relação aos métodos estudados para a determinação dos teores de metais pesados no solo (Quadro 4), constatou-se que, exceto para o $\mathrm{Cd}$, houve diferença $(p<0,01)$ entre eles. No método descrito por Jackson (1958), os teores médios de $\mathrm{Cr}, \mathrm{Pb}$ e $\mathrm{Zn}$ foram de 72,4, 31,8 e 62,3\%, respectivamente, superiores aos teores encontrados no método da USEPA-3050. Esses resultados corroboram os encontrados por Melo et al. (2007), os quais obtiveram, por meio do método descrito em Jackson (1958), teores de Ni no solo 47,0 \% superiores aos determinados pelo método USEPA-3050, mostrando que tal método não determinava todo o metal presente nas amostras de solo.

Revoredo \& Melo (2006), estudando a aplicação de lodo de esgoto contaminado com doses de $\mathrm{Ni}$ em Latossolo Vermelho distrófico, verificaram que parte do Ni das amostras de solo obtidas imediatamente após a incorporação dos respectivos tratamentos não foram determinadas pelo método USEPA-3050. Esses autores atribuíram esse fato a quantidades de $\mathrm{Ni}$ ligados a frações insolúveis que não são detectadas por esse método. Dessa forma, verifica-se que, com a utilização do método adotado pela USEPA-3050, subestimam-se as quantidades de metais pesados aplicados aos solos agrícolas via lodo de esgoto.
As doses de lodo de esgoto aplicadas durante nove anos consecutivos não influenciaram a produtividade do milho (Quadro 5), o que pode ser atribuído a um nível razoável de fertilidade no solo em razão dos cultivos e das aplicações de lodo de esgoto. Nesse sentido, Melo \& Marques (2000) relataram a importância do lodo na ciclagem de nutrientes de plantas e do aumento da disponibilidade desses elementos, promovendo, com isso, melhoria na fertilidade do solo e aumento na produtividade das culturas.

Anjos \& Mattiazzo (2000) e Nogueira et al. (2006) também não encontraram diferenças na produtividade de grãos de milho dos tratamentos com lodo de esgoto e adubação convencional. Entretanto, Melo et al. (2007) observaram que a utilização do lodo (67,5 t ha-1, base seca) como fertilizante para a cultura do milho propiciou produtividade de grãos superior $\left(8,6 \mathrm{t} \mathrm{ha}^{-1}\right)$ às obtidas com aplicação de adubos minerais $\left(5,6 \mathrm{t} \mathrm{ha}^{-1}\right)$. Silva et al. (2002) também verificaram maior produtividade de grãos de milho $\left(6,2 \mathrm{t} \mathrm{ha}^{-1}\right) \mathrm{em}$ relação à testemunha absoluta $\left(2,2 \mathrm{tha}^{-1}\right) \mathrm{e}$ à adubação NPK (3,9 a 4,7 $\left.\mathrm{t} \mathrm{ha}^{-1}\right)$ por três anos, após uma única aplicação de lodo, demonstrando seu efeito residual. Já Lemainski \& Silva (2006), utilizando lodo de esgoto da CAESB, concluíram que, em média, o lodo foi $21 \%$ mais eficiente na produção de grãos de milho, quando comparado ao fertilizante mineral, obtendo produtividade média de dois cultivos acima de $6,50 \mathrm{t} \mathrm{ha}^{-1}$ nas doses de 30 e $45 \mathrm{t} \mathrm{ha}^{-1}$ de lodo de esgoto úmido.

Em relação à produção de matéria seca pelas plantas de milho (Quadro 5), verificou-se que, exceto 
Quadro 5. Produtividade de grãos e matéria seca de partes de plantas de milho cultivadas em Latossolo Vermelho eutroférrico no nono ano de aplicação de lodo de esgoto

\begin{tabular}{|c|c|c|c|c|c|c|}
\hline Lodo de esgoto $^{(1)}$ & Produtividade & Colmo & Folhas & Palha & Sabugo & Grãos \\
\hline & $\mathrm{t} \mathrm{ha}^{-1}$ & \multicolumn{5}{|c|}{ g planta ${ }^{-1}$} \\
\hline $0,0 \mathrm{t} \mathrm{ha}^{-1(2)}$ & $5,84 \mathrm{a}$ & $31,8 \mathrm{a}$ & $25,8 \mathrm{a}$ & $11,3 \mathrm{ab}$ & $17,2 \mathrm{a}$ & $88,0 \mathrm{a}$ \\
\hline $45,0 \mathrm{t} \mathrm{ha}^{-1}$ & $5,51 \mathrm{a}$ & $27,8 \mathrm{a}$ & $22,5 \mathrm{a}$ & $10,2 \mathrm{~b}$ & $13,2 \mathrm{a}$ & $69,5 \mathrm{a}$ \\
\hline $90,0 \mathrm{tha}^{-1}$ & $6,29 \mathrm{a}$ & $33,3 \mathrm{a}$ & $25,7 \mathrm{a}$ & $13,5 \mathrm{a}$ & $17,2 \mathrm{a}$ & $94,0 \mathrm{a}$ \\
\hline $127,5 \mathrm{t} \mathrm{ha}^{-1}$ & $6,06 \mathrm{a}$ & $33,3 \mathrm{a}$ & $23,5 \mathrm{a}$ & $12,2 \mathrm{ab}$ & $17,5 \mathrm{a}$ & $84,7 \mathrm{a}$ \\
\hline $\mathrm{CV}(\%)$ & 13,4 & 12,5 & 11,7 & 15,0 & 15,0 & 16,2 \\
\hline
\end{tabular}

${ }^{(1)}$ Doses acumuladas por nove aplicações anuais. ${ }^{(2)}$ Testemunha: somente com fertilização mineral. Médias seguidas de mesma letra não diferem entre si pelo teste de Tukey a $5 \%$.

para a palha, todas as partes estudadas não apresentaram diferença entre os tratamentos. Observou-se também que, exceto para o tratamento 45,0 t ha-1 de lodo de esgoto, os resultados obtidos com a aplicação de lodo de esgoto, quando não foram superiores, mantiveram-se equiparados aos valores obtidos pela fertilização mineral, mostrando a contribuição deste resíduo para a produção de matéria seca em plantas de milho. Os resultados encontrados são concordantes com os apresentados por Melo (2002), que verificou efeitos satisfatórios em relação à produção de matéria seca de plantas de milho cultivadas em solo que recebeu aplicação de lodo de esgoto por três anos consecutivos. No Brasil, há diversos trabalhos que evidenciam aumentos na produção de matéria seca da cultura do milho quando cultivada em solos tratados com lodo de esgoto (Simonete et al., 2003; Nascimento et al., 2004). Em alguns casos, os aumentos são superiores aos obtidos com a adubação mineral recomendada para a cultura (Galdos et al., 2004).

Quanto aos teores de $\mathrm{Cd}, \mathrm{Cr}, \mathrm{Pb}$ e $\mathrm{Zn}$ nas plantas de milho (Quadro 6), apenas o Cd não foi detectado em todas as partes estudadas, indicando baixo risco de contaminação de plantas por $\mathrm{Cd}$, com a aplicação do lodo de esgoto da ETE de Barueri neste experimento. Entretanto, isso não significa que esse elemento não estivesse presente no material vegetal, e sim que sua concentração estava abaixo de $0,06 \mathrm{mg} \mathrm{kg}^{-1}$ no grão e $0,2 \mathrm{mg} \mathrm{kg}^{-1}$ nas demais partes. Gomes et al. (2006), avaliando a distribuição de metais pesados em partes (colmo, folhas, pendão, palha e grãos) de plantas de milho cultivadas em Argissolo tratado com lodo de esgoto, verificaram que, com exceção do colmo, a partir do tratamento 15,4 t ha ${ }^{-1}$ de lodo, não foi detectada a presença de Cd. Esses autores atribuíram esse fato ao baixo teor desse elemento adicionado ao solo via lodo de esgoto.

O Cr não foi detectado na palha, no sabugo e nos grãos (Quadro 6), estando os teores desse elemento abaixo de $0,3 \mathrm{mg} \mathrm{kg}^{-1}$ na palha e no sabugo e de $0,09 \mathrm{mg} \mathrm{kg}^{-1}$ nos grãos. Esses resultados corroboram, em parte, os encontrados por Melo (2002), que, estudando os teores de $\mathrm{Cu}, \mathrm{Cr}$, Mn e $\mathrm{Zn}$ nessa mesma área, porém no terceiro ano de cultivo, não detectou teores de $\mathrm{Cr}$ nas plantas de milho. Os teores de $\mathrm{Cr}$ no colmo e nas folhas variaram entre os tratamentos, sendo a dose de 90,0 $\mathrm{t} \mathrm{ha}^{-1}$ de lodo de esgoto a que promoveu os maiores teores desse elemento na planta.

Em relação aos teores de $\mathrm{Pb}$, verificou-se que esse elemento só não foi detectado nos grãos $\left(<0,4 \mathrm{mg} \mathrm{kg}^{-1}\right)$ e que, exceto no sabugo, as demais partes das plantas foram influenciadas pelos tratamentos aplicados, sendo a dose de 90,0 t ha ${ }^{-1}$ de lodo de esgoto a que promoveu os maiores teores desse elemento na planta (Quadro 6). Segundo Kabata-Pendias \& Pendias (2001), o teor foliar do $\mathrm{Pb}$ em milho considerado fitotóxico é de $56,0 \mathrm{mg} \mathrm{kg}^{-1}$. Os teores encontrados neste estudo estavam abaixo desse valor em todos os tratamentos.

Os teores de $\mathrm{Zn}$ nas partes da planta, exceto nos grãos, aumentaram com as doses de lodo de esgoto aplicadas (Quadro 6). Tal fato sugere que uma fração do $\mathrm{Zn}$ contido no lodo de esgoto torna-se disponível para a planta de milho, de forma que o aumento na dose do resíduo causa aumento no teor disponível no solo e sua absorção pela planta. Diversos autores relataram incrementos nos teores de Zn em partes de plantas de milho cultivadas em solo tratado sucessivamente com lodo de esgoto (Reddy et al., 1989; Jarausch-Wehuheim et al., 1999; Rangel et al., 2006). Entretanto, fatores como estágio de desenvolvimento da planta, tempo de exposição e espécies químicas dos elementos interferem na distribuição dos metais pesados nas plantas (Alloway, 1995).

Embora a adição de lodo tenha aumentado os teores de Zn na planta, os valores encontrados nas folhas estavam dentro da faixa considerada adequada (15,0 a 100,0 $\mathrm{mg} \mathrm{kg}^{-1}$ ) para a cultura (Cantarella et al., 1997). Além disso, cabe ressaltar que os teores de $\mathrm{Zn}$ nos grãos estavam abaixo do limite máximo de tolerância (50,0 mg kg-1) em alimentos (matéria seca) e grãos de cereais estabelecido pela Agência Nacional de Vigilância Sanitária (ANVISA), Decreto nº 55.871, 
de 26 de março de 1965 (ANVISA, 1965), ainda em vigor, e pela Associação Brasileira das Indústrias da Alimentação (ABIA, 1985).

De modo geral, o aumento das doses de lodo de esgoto promoveu acúmulo de $\mathrm{Cr}, \mathrm{Pb}$ e $\mathrm{Zn}$ nas partes da planta (Quadro 6). O Cr não foi detectado na palha, no sabugo e nos grãos, mostrando sua baixa mobilidade na planta. Em geral, o $\mathrm{Cr}$ absorvido permanece em maior proporção nas raízes, sendo pouco transportado à longa distância para a parte aérea (Kabata-Pendias \& Mukherjee, 2007), caracterizando esse fenômeno como um mecanismo de tolerância ao excesso de Cr nas plantas (Adriano, 2001).

Os maiores acúmulos de $\mathrm{Pb}$ nas partes das plantas foram observados no tratamento que recebeu 90,0 t ha-1 de lodo de esgoto (Quadro 6). Exceto para o sabugo, todas as partes analisadas apresentaram comportamento semelhante. Houve maior acúmulo desse elemento na palha, evidenciando translocação e redistribuição do $\mathrm{Pb}$ na planta, porém não atingindo os grãos, o que até certo ponto já era esperado, conforme considerações feitas por Malavolta (2006). Segun- do este autor, o $\mathrm{Pb}$ se acumula na endoderme, que atua como barreira parcial, e nas paredes da célula das raízes, e, em certas condições, formam-se precipitados amorfos identificados como fosfato de chumbo, no caso do milho. De forma concordante, Berton (1989) relata que, dentro da planta, alguns metais concentram-se nas raízes, não sendo assim transportados para a parte aérea. Várias plantas, como a soja e o milho, excluem esses elementos dos grãos.

Além disso, no solo, a forte retenção do $\mathrm{Pb}$ controla sua disponibilidade, ao contrário do que acontece, por exemplo, com o $\mathrm{Cd}$. O fato de o $\mathrm{Pb}$ usualmente não se acumular nos grãos de milho (Gerhardsson, 2004) torna-se outro fator para menor preocupação, com relação a essa cultura. Dessa forma, o sistema soloplanta é uma importante barreira para a entrada desses metais na cadeia alimentar, o que reduz os problemas com $\mathrm{Pb}$, por exemplo. Contudo, conforme Antosiewicz (1992), nem todos os metais pesados são igualmente retidos nas raízes das plantas, sugerindo que a tolerância a determinado elemento não garante, necessariamente, a tolerância a outro.

Quadro 6. Teor e acúmulo de cromo, chumbo e zinco em partes de plantas de milho cultivadas em Latossolo Vermelho eutroférrico no nono ano de aplicação de lodo de esgoto

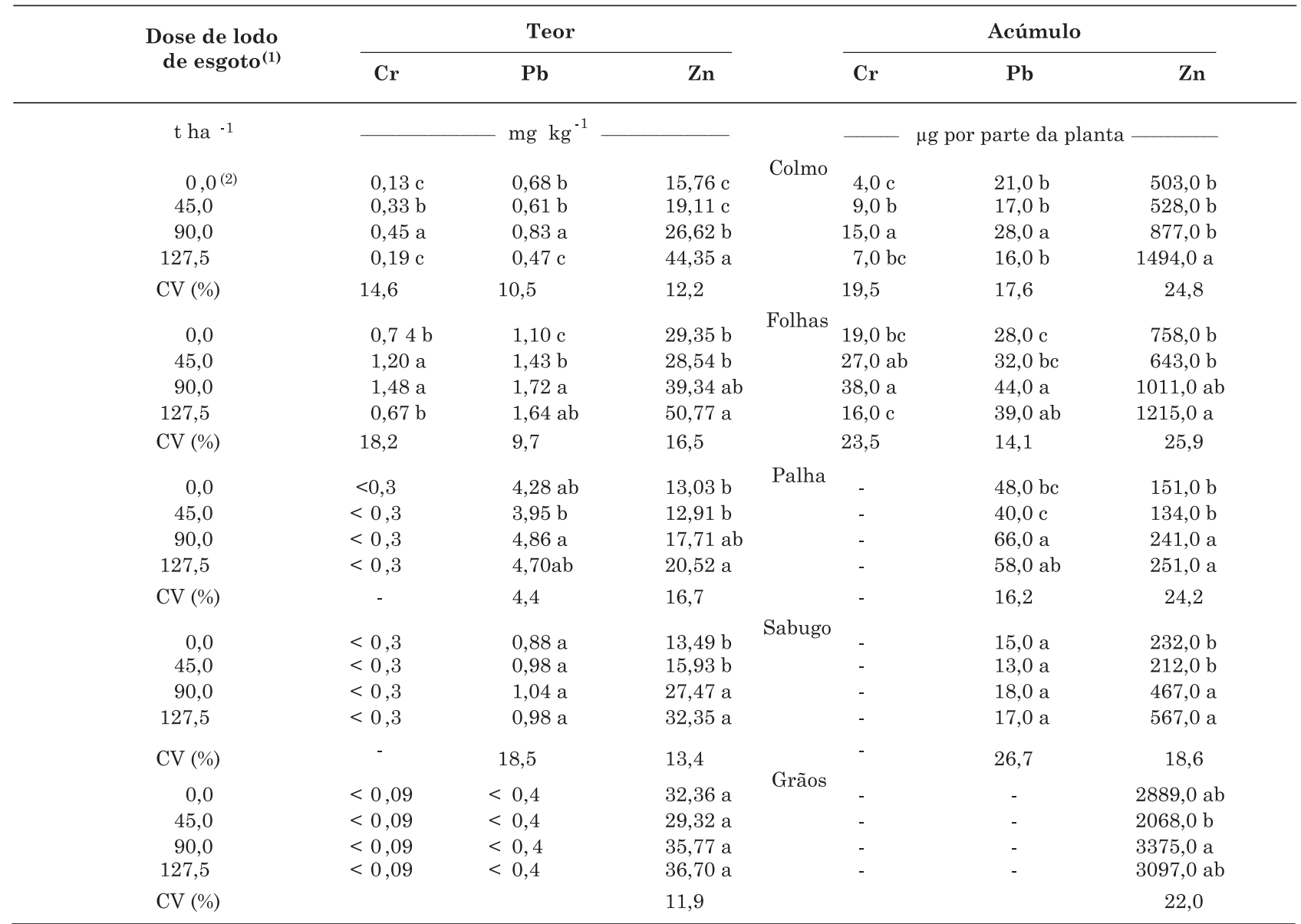

(1) Doses acumuladas por nove aplicações anuais. ${ }^{(2)}$ Testemunha: somente com fertilização mineral. Médias seguidas de mesma letra na vertical não diferem entre si pelo teste de Tukey a $5 \%$. 
Houve aumento do Zn acumulado na parte aérea das plantas em função das doses de lodo de esgoto (Quadro 6). No colmo, a maior dose de lodo foi a que promoveu o maior acúmulo de Zn (1494,0 $\left.\mu \mathrm{g} \mathrm{planta}^{-1}\right)$. Nas folhas, os valores acumulados tiveram o mesmo comportamento, entre tratamentos, como observado para os teores de Zn, evidenciando que não houve efeito da matéria seca para este elemento (Quadro 5). Exceto para os grãos, o mesmo comportamento foi verificado para a palha e o sabugo (Quadro 6). Observou-se também escala decrescente dos valores acumulados de Zn (grão > folha $>$ colmo $>$ sabugo $>$ palha) para todos os tratamentos testados. Melo (2002) encontrou distribuição semelhante de Zn em plantas de milho no terceiro ano de cultivo nessa mesma área de estudo. Por outro lado, no estudo de Gomes et al. (2006), o Zn acumulou-se preferencialmente na palha, nas folhas, no colmo e no pendão.

$\mathrm{O}$ incremento do acúmulo de $\mathrm{Zn}$ nas plantas de milho com o aumento das doses de lodo, como discutido anteriormente, está associado ao aumento da forma disponível desse elemento no solo. Esses resultados corroboram os encontrados por Galdos et al. (2004), fazendo-se, então, necessário o monitoramento constante dos teores de elementos-traço, em que o lodo de esgoto é aplicado, para que haja controle adequado dos teores de metais no solo. Berton et al. (1989) e Nascimento et al. (2004), trabalhando com doses de lodo de esgoto que variaram entre 0,0 e 80,0 $\mathrm{tha}^{-1}$, também observaram incremento na absorção de $\mathrm{Zn}$ em plantas de milho em função do aumento das doses de lodo aplicadas ao solo.

Não foram verificadas correlações entre os teores de $\mathrm{Cd}\left(\mathrm{r}=0,42\right.$; teste t para $\left.\mathrm{r}=1,96^{\mathrm{NS}}\right)$ e $\mathrm{Cr}(\mathrm{r}=0,33$; teste $t$ para $r=1,50^{\mathrm{NS}}$ ) no solo quando determinados pelos métodos de digestão USEPA-3050 e Jackson (1958). Entretanto, observou-se correlação positiva para os teores de $\mathrm{Pb}$ (Figura 1a) e de Zn (Figura 1b), indicando, nesse caso, que o método USEPA-3050 poderia ser usado em vez do método de Jackson para a extração desses elementos no solo.
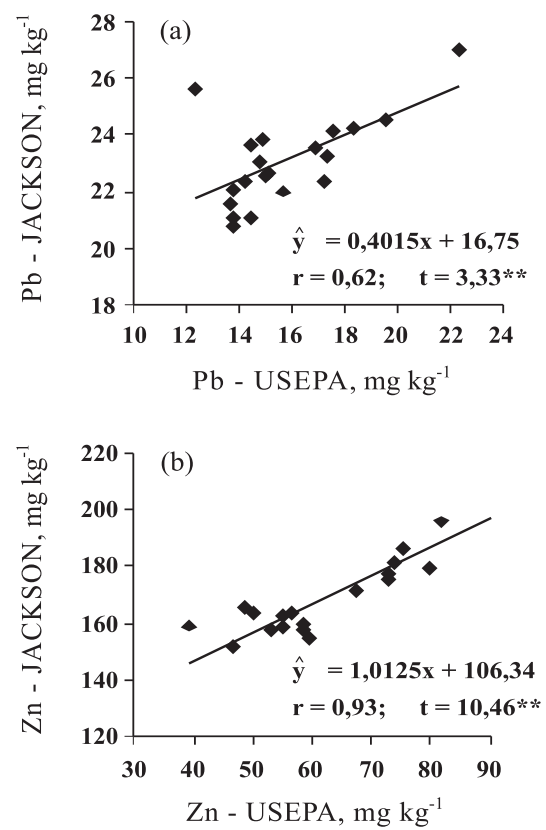

Figura 1. Correlação entre os teores de $\mathrm{Pb}(\mathrm{a})$ e $\mathrm{Zn}$ (b) extraídos pelos métodos USEPA-3050 e $\mathrm{HClO}_{4}+\mathrm{HF}$ (Jackson, 1958) em Latossolo Vermelho eutroférrico tratado com fertilizante mineral e lodo de esgoto. **: significativo a $1 \%$.

Os teores de $\mathrm{Cd}, \mathrm{Cr}, \mathrm{Pb}$ e Zn no solo, obtidos pelos dois métodos de digestão (USEPA-3050 e Jackson), não apresentaram correlação com a produtividade de grãos de milho. Além disso, exceto para o $\mathrm{Cr}$, observouse que os teores de $\mathrm{Pb}$ e $\mathrm{Zn}$ no solo correlacionaram-se de forma distinta com as quantidades acumuladas desses elementos nas plantas (Quadro 7). As correlações entre os teores dos metais no solo e seus acúmulos nas plantas já eram previstas, uma vez que as adições anuais de lodo aplicadas ao solo tenderiam a aumentar os teores disponíveis desses elementos, aumentando sua biodisponibilidade.

A absorção dos elementos pelas plantas ocorre a partir da solução do solo, permitindo inferir que o teor

Quadro 7. Coeficientes de correlação de Pearson entre os teores de $\mathrm{Pb}, \mathrm{Cr}$ e $\mathrm{Zn}\left(\mathrm{mg} \mathrm{kg}^{-1}\right)$ em Latossolo Vermelho eutroférrico e suas quantidades acumuladas ( $\mu$ g por parte da planta) nas plantas, entre teor e a produtividade de grãos de milho $\left(\mathrm{t} \mathrm{ha}^{-1}\right)$

\begin{tabular}{|c|c|c|c|c|c|c|c|}
\hline Método de extração & Colmo & Folhas & Palha & Sabugo & Grãos & PA & Produtividade \\
\hline $\mathrm{HNO}_{3}+\mathrm{H}_{2} \mathrm{O}_{2}+\mathrm{HCl}^{(1)}$ & $0,22^{\mathrm{NS}}$ & $0,39^{\mathrm{NS}}$ & $0,46^{*}$ & $\begin{array}{l}\text { Chumbo } \\
0,49^{*}\end{array}$ & $\mathrm{Nd}$ & $0,49^{*}$ & $-0,15^{\mathrm{NS}}$ \\
\hline $\mathrm{HClO}_{4}+\mathrm{HF}^{(2)}$ & $-0,15^{\mathrm{NS}}$ & $-0,29^{\mathrm{NS}}$ & $0,29^{\mathrm{NS}}$ & $\begin{array}{l}0,16 \mathrm{NS} \\
\text { Cromo }\end{array}$ & $\mathrm{Nd}$ & $0,32^{\mathrm{NS}}$ & $-0,15^{\mathrm{NS}}$ \\
\hline $\mathrm{HNO}_{3}+\mathrm{H}_{2} \mathrm{O}_{2}+\mathrm{HCl}$ & $0,17^{\mathrm{NS}}$ & $-0,03^{\mathrm{NS}}$ & $\mathrm{Nd}$ & $\mathrm{Nd}$ & $\mathrm{Nd}$ & $0,03^{\mathrm{NS}}$ & $0,08^{\mathrm{NS}}$ \\
\hline $\mathrm{HClO}_{4}+\mathrm{HF}$ & $0,28^{\mathrm{NS}}$ & $0,18^{\mathrm{NS}}$ & $\mathrm{Nd}$ & $\begin{array}{c}\mathrm{Nd} \\
\text { Zinco }\end{array}$ & $\mathrm{Nd}$ & $0,27^{\mathrm{NS}}$ & $0,10^{\mathrm{NS}}$ \\
\hline $\mathrm{HNO}_{3}+\mathrm{H}_{2} \mathrm{O}_{2}+\mathrm{HCl}$ & $0,52^{*}$ & $0,49^{*}$ & $0,60^{* *}$ & $0,64^{* *}$ & $0,56^{*}$ & $0,65^{* *}$ & $0,09^{\mathrm{NS}}$ \\
\hline $\mathrm{HClO}_{4}+\mathrm{HF}$ & $0,38^{\mathrm{NS}}$ & $0,43^{\mathrm{NS}}$ & $0,49^{*}$ & $0,60^{* *}$ & $0,37^{\mathrm{NS}}$ & $0,48^{*}$ & $0,08^{\mathrm{NS}}$ \\
\hline
\end{tabular}

${ }^{(1)}$ Método USEPA-3050. ${ }^{(2)}$ Método descrito por Jackson (1958). PA: parte aérea (soma de todas as partes das plantas). ${ }^{* *},{ }^{*} \mathrm{e}^{\mathrm{NS}}$ : significativo a 1 e $5 \%$, e não-significativo, respectivamente. Nd: não determinado. 
total de metais pesados no solo não pode ser empregado como um indicativo da fitodisponibilidade (Pires et al., 2006). Para isso, vêm sendo estudados diversos extratores químicos, cuja eficiência é atribuída de acordo com o grau de correlação entre quantidades extraídas do solo e quantidades absorvidas pelas plantas.

\section{CONCLUSÕES}

1. As doses de lodo de esgoto aplicadas por nove anos consecutivos não influenciaram os teores de $\mathrm{Cd}$, $\mathrm{Cr}$ e $\mathrm{Pb}$ no solo, entretanto, promoveram o incremento nos teores de Zn no solo.

2. Os teores médios de $\mathrm{Cr}, \mathrm{Pb}$ e $\mathrm{Zn}$ no solo obtidos pela digestão com $\mathrm{HClO}_{4}+\mathrm{HF}$ foram superiores àqueles encontrados pelo ataque com $\mathrm{HNO}_{3}+\mathrm{H}_{2} \mathrm{O}_{2}+$ $\mathrm{HCl}$.

3. Os teores e os acúmulos de $\mathrm{Cr}, \mathrm{Pb}$ e $\mathrm{Zn}$ nas partes das plantas de milho foram incrementados pelas sucessivas aplicações de lodo de esgoto ao solo.

4. Os teores de $\mathrm{Cd}, \mathrm{Cr}, \mathrm{Pb}$ e $\mathrm{Zn}$ nos grãos, quando detectados, permaneceram abaixo dos limites máximos estabelecidos para o consumo humano conforme a legislação brasileira.

5. A aplicação sucessiva do lodo foi tão efetiva quanto a adubação mineral na produção de matéria seca e de grãos de milho.

\section{AGRADECIMENTOS}

À Fundação de Amparo à Pesquisa do Estado de São Paulo (FAPESP), pelo suporte financeiro e pela bolsa de Mestrado (Ref. Proc. 6/54620-6) concedida ao primeiro autor.

\section{LITERATURA CITADA}

ASSOCIAÇÃO BRASILEIRA DAS INDÚSTRIAS DA ALIMENTAÇÃO - ABIA. Compêndio da legislação dos alimentos. São Paulo, 1985. Não Paginado.

ABREU, C.A.; BERTON, R.S. \& ANDRANDE, J.C. Comparison of methods to evaluate heavy metals in organic wastes. Comm. Soil Sci. Plant Anal., 27:1125-1153, 1996.

ADRIANO, D.C. Trace elements in terrestrial environments Biogeochemistry, bioavailability, and risks of metals. 2.ed. New York, Springer-Verlag, 2001. 867p.

ALLOWAY, B.J. Heavy metals in soils. 2.ed. New York, Blackie Academic \& Professional, 1995. 368p.

ANJOS, A.R.M. \& MATTIAZZO, M.E. Lixiviação de íons inorgânicos em solos repetidamente tratados com biossólidos. R. Bras. Ci. Solo, 24:927-938, 2000.
ANTOSIEWICZ, D.M. Adaptation of plants to an environment polluted with heavy metals. Acta Soc. Botanicorum Poliniae, 61:281-299, 1992.

ANVISA. Decreto n ${ }^{\circ} 55.871$, de 26 de março de 1965. Disponível em: <http://www.anvisa.gov.br/legis/decretos/ 55871_65.htm>. Acesso em: 4 de maio de 2008.

BERTON, R.S. Especiação iônica da solução do solo: Metodologia e aplicações. In: SIMPÓSIO AVANÇADO DE SOLOS E NUTRIÇÃO DE PLANTAS, 1., Piracicaba, 1989. Anais. Campinas, Fundação Cargil, 1989. p.17-41.

BERTON, R.S.; CAMARGO, O.A. \& VALADARES, J.M.A.S. Absorção de nutrientes pelo milho em resposta à adição de lodo de esgoto a cinco solos paulistas. R. Bras. Ci. Solo, 13:187-192, 1989.

BRASIL. Ministério da Agricultura e Reforma Agrária. Regras para análise de sementes. Brasília, 1992. 365p.

BREMNER, J.M. Nitrogen-total. In: SPARKS, D.L.; PAGE, A.L.; HELMKE, P.A.; LOEPPERT, R.H.; SOLTANPOUR, P.N.; TABATABAI, M.A.; JOHNSTON, C.T. \& SUMNER, M.E., eds. Methods of soil analysis. Chemical methods. Madison, Soil Science Society of America, 1996. Part 3. p.1085-1121.

CANTARELLA, H.; RAIJ, B.van \& CAMARGO, C.E.O. Cereais. In: RAIJ, B.van; CANTARELLA, H.; QUAGGIO, J.A. \& FURLANI, A.M.C. Recomendações de adubação e calagem para o Estado de São Paulo. 2.ed. Campinas, Instituto Agronômico de Campinas, 1997. p.45-71. (Boletim Técnico, 100)

COMPANHIA DE TECNOLOGIA DE SANEAMENTO AMBIENTAL - CETESB. Critérios para aplicação de biossólidos em áreas agrícolas: critérios para projeto e operação. Norma P 4.230. São Paulo, CETESB, 1999. 32p. (Manual Técnico).

COMPANHIA DE TECNOLOGIA DE SANEAMENTO AMBIENTAL - CETESB. Decisão de diretoria $\mathrm{N}^{\circ} 195$-2005E, de 23 de novembro de 2005. Disponível em: <http:// www.cetesb.sp.gov.br/Solo/relatorios/ tabela_valores_2005.pdf>. Acesso em: 5 de março de 2007.

CONSELHO NACIONAL DO MEIO AMBIENTE - CONAMA. Resolução $\mathrm{n}^{\circ}$ 375, de 29 de agosto de 2006. Disponível em: $<$ http://www.mma.gov.br/port/conama/res/res06/ res37506.pdf>. Acesso em: 5 de dez. de 2007.

EMPRESA BRASILEIRA DE PESQUISA AGROPECUÁRIA EMBRAPA. Sistema brasileiro de classificação de solos. 2.ed. Rio de Janeiro, Embrapa Solos, 2006. 306p.

ESTAT: Sistema de análises estatísticas. Jaboticabal, Universidade Estadual de São Paulo, 1994.

FERREIRA, A.C.; ANDREOLI, C.V. \& LARA, A.I. Riscos associados ao uso do lodo de esgoto. In: PROGRAMA DE PESQUISA EM SANEAMENTO BÁSICO - PROSAB. Uso e manejo do lodo de esgoto na agricultura. Rio de Janeiro, 1999. p.29-33.

GALDOS, M.V.; DE MARIA, I.C. \& CAMARGO, O.A. Atributos químicos e produção de milho em um Latossolo Vermelho eutroférrico tratado com lodo de esgoto. R. Bras. Ci. Solo, 28:569-577, 2004 
GERHARDSSON, L. Lead. In: MERIAN, E.; ANKE, M.; IHNAT, M. \& STOEPPLER, M. Elements and their compounds in the environment. 2.ed. Weinheim, Verlag GmbH, 2004. p.879-900.

GINÉ-ROSIAS, M.F. Espectrometria de emissão atômica com plasma acoplado indutivamente (ICP-AES). CENA, 3:125128, 1998. (Série Didática)

GOMES, S.B.V.; NASCIMENTO, C.W.A.; BIONDI, C.M. \& ACCIOLY, A.M.A. Distribuição de metais pesados em plantas de milho cultivadas em Argissolo tratado com lodo de esgoto. Ci. Rural, 36:1689-1695, 2006.

JACKSON, M.L. Soil chemical analysis. Englewood Cliffs, Prentice-Hall, 1958. 498p.

JARAUSCH-WEHRHEIM, B.; MOCQUOT, B. \& MENCH, M. Absorption and translocation of sludge-borne zinc in fieldgrown maize (Zea mays L.). Eur. J. Agron., 11:23-33, 1999.

JEEVAN RAO, K. \& SHANTARAM, M.V. Effect of urban solid wastes on dry matter yield, uptake of micronutrients and heavy metals by maize plants. J. Environ. Biol., 17:25$32,1996$.

KABATA-PENDIAS, A. \& PENDIAS, H. Trace elements in soils and plants. 3.ed. Boca Raton, CRC Press, 2001. 413p.

KABATA-PENDIAS, A. \& MUKHERJEE, A.B. Trace elements from soil to human. New York, Springer-Verlag, 2007. $550 \mathrm{p}$.

KREBS, R.; GUPTA, S.K.; FURRER, G. \& SCHULIN, R. Solubility and plant uptake of metals with and without liming of sludge-amended soils. J. Environ. Qual., 27:1823,1998

LEMAINSKI, J. \& SILVA, J.E. Utilização do biossólido da CAESB na produção de milho no Distrito Federal. R. Bras. Ci. Solo, 30:741-750, 2006.

MALAVOLTA, E.; VITTI, G.C. \& OLIVEIRA, S.A. Avaliação do estado nutricional das plantas: Princípios e aplicações. 2.ed. Piracicaba, Associação Brasileira para Pesquisa da Potassa e do Fosfato, 1997. 319p.

MALAVOLTA, E. Elementos benéficos e tóxicos. In: MALAVOLTA, E. Manual de nutrição mineral de plantas. São Paulo, Agronômica Ceres, 2006. p.418-511.

MARTINS, A.L.C.; BATAGLIA, O.C. \& CAMARGO, O.A. Copper, nickel and zinc phytoavailability in an Oxisol amended with sewage sludge and liming. Sci. Agric., 60:747-754, 2003.

MELO, V.P. Propriedades químicas e disponibilidade de metais pesados para a cultura de milho em dois Latossolos que receberam adição de lodo de esgoto. Jaboticabal, Universidade Estadual Paulista, 2002. 134p. (Tese de Mestrado)

MELO, W.J. \& MARQUES, M.O. Potencial do lodo de esgoto como fonte de nutrientes para as plantas. In: BETTIOL, W. \& CAMARGO, O.A., eds. Impacto ambiental do uso agrícola do lodo de esgoto. Jaguariúna, Embrapa Meio Ambiente, 2000. p.109-142.
MELO, W.J.; AGUIAR, P.S.; MELO, G.M.P. \& MELO, V.P. Nickel in a tropical soil treated with sewage sludge and cropped with maize in a long-term field study. Soil Biol. Biochem., 39:1341-1347, 2007.

NASCIMENTO, C.W.A.; BARROS, D.A.S.; MELO, E.E.C. \& OLIVEIRA, A.B. Alterações químicas em solos e crescimento de milho e feijoeiro após aplicação de lodo de esgoto. R. Bras. Ci. Solo, 28:385-392, 2004.

NOGUEIRA, T.A.R.; SAMPAIO, R.A.; FERREIRA, C.S. \& FONSECA, I.M. Produtividade de milho e de feijão consorciados adubados com diferentes formas de lodo de esgoto. R. Biol. Ci. Terra, 6:122-131, 2006.

NOGUEIRA, T.A.R.; SAMPAIO, R.A.; FONSECA, I.M.; FERREIRA, C.S.; SANTOS, S.E.; FERREIRA, L.C.; GOMES, E. \& FERNANDES, L.A. Metais pesados e patógenos em milho e feijão caupi consorciados, adubados com lodo de esgoto. R. Bras. Eng. Agric. Amb., 11:331338, 2007.

OLIVEIRA, F.C. \& MATIAZZO, M.E. Metais pesados em Latossolo tratado com lodo de esgoto e em plantas de cana-de-açúcar. Sci. Agric., 58:581-593, 2001.

OLIVEIRA, K.W.; MELO, W.J.; PEREIRA, G.T.; MELO, V.P. \& MELO, G.P. Heavy metals in oxisols amended with biosolids and cropped with maize in a long-term experiment. Sci. Agric., 62:381-388, 2005.

PIMENTEL-GOMES, F. \& GARCIA, C.H. Estatística aplicada a experimentos agronômicos e florestais: Exposição com exemplos e orientações para uso de aplicativos. Piracicaba, FEALQ, 2002. 309p.

PIRES, A.M.M.; ANDRADE, C.A. \& COSCIONE, A.R. Metais pesados em solos tratados com lodo de esgoto. In: SPADOTTO, C.A. \& RIBEIRO, W.C., eds. Gestão de resíduos na agricultura e agroindústria. Botucatu, FEPAF, 2006. p.205-232.

RAIJ, B.van; ANDRANDE, J.C.; CANTARELLA, H. \& GUAGGIO, J.A. Análise química para avaliação da fertilidade de solos tropicais. Campinas, Instituto Agronômico de Campinas, 2001. 285p.

RAIJ, B.van \& CANTARELlA, H. Milho. In: RAIJ, B.van; CANTARELLA, H.; QUAGGIO, J.A. \& FURLANI, A.M.C. Recomendações de adubação e calagem para o Estado de São Paulo. 2.ed. Campinas, Instituto Agronômico de Campinas, 1997. p. 56-59. (Boletim Técnico, 100)

RANGEL, O.J.P.; SILVA, C.A.; BETTIOL, W.; GUILHERME, L.R.G. \& DYNIA, J.F. Acúmulo de $\mathrm{Cu}, \mathrm{Mn}, \mathrm{Ni}, \mathrm{Pb}$ e Zn EM Latossolo Vermelho adubado com fontes de lodo de esgoto e cultivado com milho. Ci. Agrotéc., 28:15-23, 2004.

RANGEL, O.J.P.; SILVA, C.A.; BETTIOL, W. \& DYNIA, J.F. Efeito de aplicações de lodo de esgoto sobre os teores de metais pesados em folhas e grãos de milho. R. Bras. Ci. Solo, 30:583-594, 2006.

REDDY, M.R.; LAMECK, D. \& REZANIA, M.E. Uptake and distribution of copper and zinc by soybean and corn from soil treated with sewage sludge. Plant Soil, 113:271-274, 1989. 
REVOREDO, M.D. \& MELO, W.J. Disponibilidade de níquel em solo tratado com lodo de esgoto e cultivado com sorgo. Bragantia, 65:679-685, 2006.

ROCHA, R.E.M.; PIMENTEL M.S.; ZAGO, V.C.P.; RUMJANEK, N.G. \& POLLI, H. Avaliação de biossólido de águas servidas domiciliares como adubo em couve. Pesq. Agropec. Bras., 38:1435-1441, 2003.

SANTOS, F.S.; AMARAL SOBRINHO, N.M.B. \& MAZUR, N. Influência de diferentes manejos agrícolas na distribuição de metais pesados no solo e em plantas de tomate. $R$. Bras. Ci. Solo, 26:535-543, 2002

SILVA, C.A.; RANGEL, O.J.P.; BETTIOL, W.; MANZATTO, C.V.; BOEIRA, R.C. \& DYNIA, F. Dinâmica de metais pesados em Latossolo adubado com lodo de esgoto e em plantas de milho. In: BETTIOL, W. \& CAMARGO, O.A., eds. Lodo de esgoto: Impactos ambientais na agricultura. Jaguariúna, Embrapa Meio Ambiente, 2006. p.45-77.
SILVA, J.E.; RESCK, D.V.S. \& SHARMA, R.D. Alternativa agronômica para o biossólido produzido no Distrito Federal. I - Efeito na produção de milho e na adição de metais pesados em Latossolo no cerrado. R. Bras. Ci. Solo, 26:487495, 2002 .

SIMONETE, M.A.; KIEHL, J.C.; ANDRADE, C.A. \& TEIXEIRA, C.F.A. Efeito do lodo de esgoto em um Argissolo e no crescimento e nutrição de milho. Pesq. Agropec. Bras., 38:1187-1195, 2003.

UNITED STATES ENVIRONMENTAL PROTECTION AGENCY - USEPA. Test method for evaluating solid wast. Washington, 1986. 152p. (Report number SW-846)

UNITED STATES ENVIRONMENTAL PROTECTION AGENCY - USEPA. Title 40 CFR - Part 503. Final rules: Standards for the use or disposal of sewage sludge. Federal Register, 58:9387-9415, 1993. 